\title{
Famílias políticas tradicionais dominam as eleições à Prefeitura de Curitiba em 2016
}

Fernando Marcelino Pereira1

- Enviado em 15/09/2016

- Aprovado em 18/09/2016
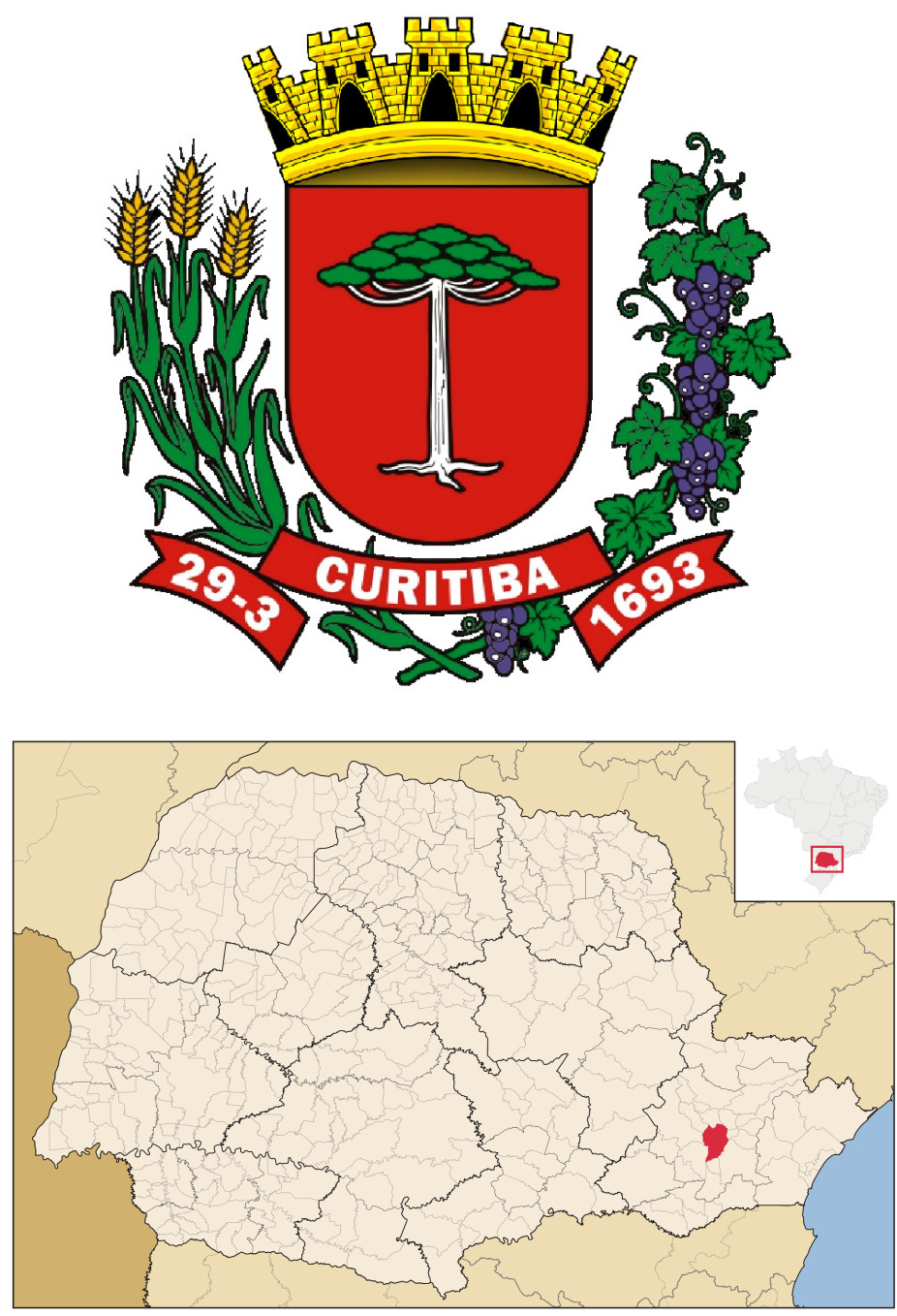

Fonte: http://www.curitiba.pr.gov.br/conteudo/simbolosbandeira-brasao-e-hino-municipal/158. 18.setembro. 2016

${ }^{1}$ Graduado em Relações Internacionais pela UniCuritiba, Mestre em Ciência Política e Doutorando em Sociologia pela UFPR. Endereço eletrônico: fernandomarcelinopereira@gmail.com 


\section{Famílias políticas tradicionais dominam as eleições à Prefeitura de Curitiba em 2016}

Fernando Marcelino Pereira

Nove candidatos disputam as eleições pela Prefeitura de Curitiba em 2016. Além do candidato a reeleição Gustavo Fruet (PDT), concorrem no pleito o ex-prefeito Rafael Greca (PMN), os deputados estaduais Requião Filho (PMDB), Ney Leprevost (PSD), Tadeu Veneri (PT) e Maria Victoria (PP), a advogada e militante feminista Xênia Mello (PSOL), o empresário Ademar Pereira (Pros) e Afonso Rangel (PRP), pró-reitor da Universidade Tuiuti do Paraná (UTP). Neste artigo analisamos a trajetória dos nove candidatos, focando suas relações de parentesco na política.

\section{Gustavo Fruet (PDT)}

Vice: Paulo Salamuni (PV)

Coligação: PDT, PV, PTB, PRB e PPS

Gustavo Fruet nasceu em Curitiba no dia 18 de abril de 1963. Filho de Maurício Fruet e Ivete Ana Bonato Fruet. Irmão de Eleonora e Cláudio Fruet.

Gustavo foi aluno do Colégio Santa Maria desde os sete anos de idade. Em 1979, aos 16 anos, se mudou a Brasília com o pai, que havia sido eleito à Câmara Federal. Pouco depois, passou no vestibular para cursar direito na Universidade de Brasília (UnB), onde foi presidente de centro acadêmico. Gustavo concluiu direito na Universidade Federal do Paraná (UFPR), com atuação política no movimento estudantil, como presidente do Centro Acadêmico Hugo Simas. Fez mestrado e doutorado também em Direito pela mesma Instituição.

0 avô de Gustavo, Constante Eugênio Fruet, foi presidente do Coritiba Foot-bool Clube em duas ocasiões, 1916-1917 e 1926. Com sua esposa, Geni Roslindo Fruet, foram dirigentes 
da Escola Dominical da Igreja Presbiteriana Independente de Curitiba do Largo da Ordem, bastante tradicional nas primeiras décadas do século passado².0 tio-avô de Gustavo, Humberto Fruet, foi o primeiro presidente do Savóia Futebol Clube, um dos primeiros clubes que deram origem ao Paraná Clube.

Gustavo entrou na política por meio do pai Maurício Fruet, ex-prefeito de Curitiba. Nascido em Curitiba, 12 de agosto de 1939, Maurício se graduou Bacharel em Ciências Jurídicas e Sociais pela UFPR, foi Vereador em Curitiba (1968-1970), deputado estadual nas gestões (1970-1974 e 1974- 1978), deputado federal (1978-1982), prefeito de Curitiba (1983-1985) e novamente deputado federal (1986-1990). Foi Secretário de Estado de Ciência e Tecnologia, no primeiro governo de Roberto Requião (1991 - 1994). Estava em campanha para voltar à Câmara dos Deputados quando faleceu em 30 de agosto de 1998 em Curitiba. A sua candidatura foi substituída pela de seu filho Gustavo Fruet, que fora eleito vereador Curitiba em 1996. Foi o segundo candidato mais votado em Curitiba, com 45.929 votos. Em 2002, foi eleito para o segundo mandato de deputado federal, com 105.166 votos. Em 2006, Gustavo Fruet reelegeu-se com 210.674 votos, que fizeram dele o deputado federal mais votado do Paraná. Nas eleições 2012, foi eleito prefeito de Curitiba para gestão 2013-2016.

Como prefeito de Curitiba entre 2012 e 2016, Gustavo Fruet indicou a esposa, Márcia Oleskovicz Fruet, para comandar a Fundação de Ação Social (FAS) e a irmã, Eleonora Fruet, para assumir a Secretaria de Finanças.

Eleonora Fruet é economista formada pela Universidade Federal do Paraná em 1988 onde foi Presidente do Centro Acadêmico de Economia. Formada começou a trabalhar na empresa Directa Auditores e Consultores (1989 a 1995), foi professora do Departamento de Economia da UFPR, nos cursos de graduação e pós-graduação em Ciências Econômicas em 1997 e 1998. Sócia-diretora da empresa de consultoria econômico-financeira Macrodinâmica. Secretária de Estado do Planejamento e Coordenação Geral do Paraná de 2003 a 2004 no Governo Requião e Secretária Municipal da Educação de Curitiba de 2005 a 2010 nos governos Beto Richa e Luciano Ducci.

\footnotetext{
${ }^{2}$ Ver o estudo "RAPOSAS E OUTSIDERS NO FUTEBOL PARANAENSE: UM ESTUDO SOBRE RELAÇÕES DE PODER E GENEALOGIA" de Luiz Demétrio Janz Laibida. Tese de doutorado em Sociologia da UFPR. 2016. Disponível em file://C:/Users/ESCRIT\%C3\%93RIO/Downloads/R\%20-\%20T\%20\%20LUIZ\%20DEMETRIO\%20JANZ\%20LAIBIDA.pdf
} 
Seu outro irmão Cláudio Bonato Fruet é bacharel em Direito pela Universidade de Brasília em 1985. Advogado do Escritório Caputo Bastos \& Fruet, como noticiado na imprensa, um dos responsáveis pela escolha dos caças Gripen da Suécia pelo governo brasileiro 3 .

A família Fruet também tem um pé no judiciário paranaense, com a juíza Beatriz Fruet, Josiene Fruet Bettini Lupion que foi Defensora-Geral do Estado do Paraná, Tânia Fruet, assessora jurídica no Tribunal de Justiça do Estado do Paraná, entre outros.

Nas eleições de 2016, Gustavo Fruet apresentou a segunda maior declaração de bens dos postulantes com R 2,9 milhões. Entre os bens de maior valor estão um apartamento (R\$ 745 mil), um fundo de investimentos no Banco do Brasil (R\$ 333,7 mil) e uma aplicação de renda fixa (R\$300 mil) no banco Itaú.

Gustavo apresentou um novo candidato a vice em 2016, o vereador Paulo Salamuni (PV). Nascido em Curitiba, Paulo cursou o 1.ำ e 2.o graus no Colégio Jesuíta Nossa Senhora Medianeira de 1967 a 1978, se formou em Direito na PUC-PR, foi Procurador do Município de Curitiba e Secretário Municipal de Desenvolvimento Social de Curitiba de 1987 a 1988. Vereador no seu 6. mandato popular consecutivo.

Paulo é filho dos professores Hôda e Riad Salamuni, um dos mais importantes geólogos paranaenses e primeiro Reitor eleito da Universidade Federal do Paraná. Riad Salamuni, descendente de libaneses, formou em 1952 em História Natural, vindo a trabalhar como assistente de professor. Estudou Geologia nos Estados Unidos nas universidades de Miami e Chicago entre 1954/55. De volta ao Brasil, apesar de ter oportunidade de trabalhar na Bahia, onde a Petrobrás implantava o primeiro curso de Geologia, Riad preferiu, por razões familiares - seu pai estava doente na época - tornar-se assistente de um geólogo amador de Ponta Grossa, Frederico Lauding, depois que o mais famoso e respeitado geólogo na época, Reinhard Maark (1891-1968), quando ele o procurou, recusou-o como assistente. Anos depois, juntos fariam importantes trabalhos científicos, inclusive no mapeamento geológico

\footnotetext{
3 Disponível em http://opiniaoenoticia.com.br/brasil/eua-ganham-bilhoes-com-venda-de-cacas-suecos/. Acesso 29 de Agosto de 2016.
} 
do Estado, área em que o Paraná foi pioneiro. Riad foi membro do antigo PSB (Partido Socialista Brasileiro), defendendo de idéias nacionalistas4.

O irmão de Paulo é Eduardo Salamuni, graduado em Geologia pela Universidade Federal do Paraná (1986), Mestre (1991) e Doutor (1999) pela Universidade Estadual Paulista Júlio de Mesquita Filho - UNESP. Professor Associado I na Universidade Federal do Paraná nos Cursos de Graduação e Pós-Graduação de Geologia. Foi Diretor Presidente da MINEROPAR de 2003 a 2011 nos governos Requião e é Chefe do Departamento de Geologia da UFPR nas Gestões 2013-2015 e 2015-2017.

\section{Rafael Greca (PMN)}

Vice: Eduardo Pimentel Slaviero (PSDB)

Coligação: PMN, PSDB, PTN, PSB, PTdoB, PSDC e DEM.

Rafael Valdomiro Greca de Macedo nasceu em Curitiba em 17 de março de 1956. É formado em Economia pela Fundação de Estudos Sociais do Paraná (FESP) em 1977, e em Engenharia Civil, com especialização em Urbanismo pela Universidade Federal do Paraná em 1978.

Formado no berço do lernismo nos anos 80, foi vereador, se elegeu prefeito (1993-96), deputado estadual, federal e chegou a ministro de Estado do Esporte e Turismo no segundo governo no governo Fernando Henrique, entre 1999 e 2000. Deixou o grupo lernista para se aliar ao do “inimigo" Roberto Requião. Deputado Estadual eleito em 2002 com 51.921 votos. Buscou a reeleição em 2006, obtendo apenas 34.736 votos, entrando no quadro de suplentes do legislativo estadual paranaense pelo PMDB. Em 2007 tomou posse como presidente da Companhia de Habitação do Paraná. Em julho de 2008 o Ministério Público (MP/PR) abriu procedimento investigatório para apurar as denúncias de que a Companhia de Habitação do Paraná (Cohapar) gastou, entre fevereiro de 2007 e abril de 2008, mais de R\$ 27 mil com despesas de alimentação de Rafael Greca. Os gastos incluem

\footnotetext{
${ }^{4}$ Disponível em http://www.millarch.org/artigo/salamuni-lembrancas-do-senhor-ex-reitor. Acesso em 27 de Agosto de 2016.
} 
refeições em restaurantes de luxo em Curitiba, como o Ille de France, especializado em cozinha internacional de alto padrão, o restaurante do Graciosa Country Club, Anarco Empório Restaurante, Ka Kiun Kim Cozinha Oriental, Estrela da Terra, La Pasta Gialla, Karbonel Frutos do Mar, Churrascaria Alto da Glória, Alma Lusa, Ponte Vecchio, Churrascaria do Erwin, entre outros ${ }^{5}$. Entre restaurantes especializados em comida japonesa, tailandesa e chinesa, foram despendidos mais de $\mathrm{R} \$ 3,2$ mil. Em quatro jantares no restaurante Ille de France teriam sido despendidos mais de $\mathrm{R} \$ 1.037$ mil. As carnes nobres eram as mais apreciadas pelo presidente da Cohapar. Somente as churrascarias de Curitiba já tiveram lucro superior a $\mathrm{R} \$ 2,4$ mil com a estatal 6 .

Rafael Greca é filho da professora Terezinha Greca de Macedo e de Eurico Dacheux de Macedo, engenheiro do Departamento de Estradas e Rodagem (DER) do Paraná. Seus avós exerceram diversas profissões, incluindo a extração de madeira, areia, erva-mate e no comércio. Rafael é casado com a jornalista Margarita Sansone.

Para as eleições de 2016, Greca disse possuir um patrimônio no valor de R\$ 573,4 mil, com 23 obras de arte, entre elas um quadro do artista plástico curitibano Sério Ferro e uma aquarela do francês radicado em Curitiba Paul Garfunkel. Também há mobílias do século 19 e duas pinhas de porcelana portuguesa. Greca disse ainda que possui $50 \%$ de um apartamento em Curitiba, no valor de apenas $\mathrm{R} \$ 22.654,65$. As benfeitorias no imóvel, segundo a declaração, valem 23.874,93. Ele também tem aplicações em CDB no Bradesco, no valor de R\$ $53.140,71$.

A ascendência da família Macedo, tem como berço a Monarquia Portuguesa do século XI, “com o nobre Gonçalo Annes Borges, décimo primeiro avô de Simão Borges de Cerqueira, pai de Maria de Cerqueira Leme a qual casou em Itú com o Fidalgo Duarte da Távora Gambôa, natural de Alhos Verdes, Portugal"7. Tiveram uma filha chamada Catharina de Macedo Baldraga, a qual matrimoniou-se com João Corrêa de Fonseca, sendo este o tronco da linhagem Macedo no Paraná. Do enlace matrimonial de João Corrêa e Catharina, tiveram

5 Disponível em http://www.bemparana.com.br/noticia/73751/mp-investiga-jantares-de-greca-pagos-pelacohapar. Acesso em 26 de Agosto de 2016.

${ }^{6}$ Disponível em http://www.bemparana.com.br/noticia/107221/mp-denunciara-greca-por-farra-na-cohapar. Acesso em 23 de Agosto de 2016.

${ }^{7}$ MACEDO E BACELLAR, Genealogia de Manoel Ribeiro de Macedo. Curitba, 1998, p.25. 
vários filhos entre eles, Maria Corrêa de Macedo que uniu-se a Manoel Ribeiro Callado, deixando descendência de seis filhos, dentre eles, Manoel Ribeiro de Macedo.

A descendência de Manoel Ribeiro de Macedo passou a ocupar os espaços sociais de decisão e prestígio diretamente vinculados ao poder político (executivo, legislativo e judiciário) e à burocracia pública. Tiveram parentes na Interventoria, no Governo do Estado, na Polícia Estadual e Federal, no Tribunal de Justiça, Tribunal de Alçada, Tribunal de Contas, Assembleia Legislativa, Prefeituras de diversos Municípios, Reitoria, Universidade Federal do Paraná, nas Secretarias do Estado, no Magistério Público, no antigo Tesouro do Estado, nas Funções Públicas e Privadas, na Indústria e no Comércio. Nestes 108 anos de Associação Comercial do Paraná, 37 foram presididos por pessoas descendentes ou ligados diretamente à Família de Manoel Ribeiro de Macedo ${ }^{8}$.

Aqueles que não possuíam vínculos matrimoniais com famílias tradicionais pertencentes à elite, tratavam de estabelecê-lo, assim a sua filha Anna Rosa de Macedo matrimoniou-se com a importante família do Tenente Coronel James Pinto de Azevedo Portugal, que vinha a ser filho do Coronel Francisco Pinto de Azevedo Portugal e, neto de Diogo Pinto de Azevedo Portugal (Conquistador Militar a serviço da Coroa Portuguesa/ Grande proprietário). Desse tronco, que reúne a família Macedo e a Azevedo Portugal terá início a linhagem mais tradicional do sistema judicial paranaense, constituindo uma estirpe ou clã de juristas composta direta ou indiretamente por sete famílias (ethos de classe/socialização no interior de uma posição social específica), entre elas a família Macedo Portugal, Azevedo Portugal, Rotoli de Macedo, Riquelme de Macedo, Pereira de Macedo, Marés de Souza e Sotto Maior9.

A família Macedo tem grande poder e influência, sendo uma das mais antigas oligarquias do Paraná. Um dos sobrenomes que continua comum entre as classes dominantes. Muito influente na Associação Comercial e no Tribunal de Justiça. Tem poder desde o período colonial, atravessando o Império e a Primeira República, no século 20. E ressurge na política de Curitiba novamente com Rafael Greca de Macedo.

\footnotetext{
8 Idem, MACEDO E BACELLAR, 1998, p.24

9 Ver estudo de Henri Kaminski sobre as famílias no sistema judicial paranaense disponível em http://acervodigital.ufpr.br/bitstream/handle/1884/31793/R\%20-\%20D\%20-

\%20HENRY\%20LEVI\%20KAMINSKI.pdf?sequence=1. Acesso em 18. Setembro.2016
} 
O vice de Rafael Greca é Eduardo Pimentel Slaviero. Nascido em 21 de setembro de 1984 em Curitiba. Filou-se ao PSDB em 2009 e passou a ser diretor de marketing da Fundação Cultural de Curitiba do governo Richa. Foi candidato em 2010 para deputado estadual, não obtendo sucesso. A disputa nas eleições de 2014 era certeira, entretanto houve a desistência por parte de Eduardo, que assumiu a Sub-chefia da Casa Civil do Paraná e depois virou Assessor Especial do Governador Richa. Eduardo é casado com a publicitária Paula Mocellin, filha de Marcos Mocellin e Stella Antunes Mocellin e neta do pediatra Irineu Antunes Filho. 0 casamento foi em 2010 no Salão Azul do Clube Curitibano.

Os avôs de Eduardo são Rubens e Ruth Slavieiro por parte de pai e Paulo e Ivone Pimentel por parte de mãe. Paulo Pimentel foi Governador do Paraná entre 1966 e 1971 pela ARENA e, por sua vez, era genro de João Lunardelli, dono das maiores proprietárias de terras e glebas no Norte do Paraná e irmão de Geremia, o "rei do café".

Os pais de Eduardo são Claudio Gomes Slavieiro e Isabel Lunardelli Pimentel. Seu pai é natural de Irati e empresário nos ramos agropecuário, de distribuição de automotivos, reflorestamento e cimento, ex-presidente da Associação Comercial do Paraná, diretor da Fiep e conselheiro do Sindicato Nacional das Industrias de Cimento. Já foi suplente do Conselho de Administração do BRDE. A família Gomes é uma das principais acionistas da Cimentos Itambé, cujo controle acionário está nas mãos de famílias paranaenses $(62 \%$ divididos entre os Slaviero, os Gomes e os Araújo). O Coronel Emílio Batista Gomes foi o primeiro prefeito de Irati, em 1907. Um dos netos dele foi o ex-Governador do Paraná, Emílio Hoffmann Gomes, eleito pela Assembleia Legislativa em 1973 e Governador até 1975 (OLIVEIRA, 2012).

Eduardo tem um irmão e uma irmã. Daniel Pimentel Slaviero que é o atual Presidente da Associação Brasileira de Emissoras de Rádio e Televisão (ABERT), iniciou sua carreira nas emissoras de televisão do Grupo Paulo Pimentel e foi diretor-executivo da Rede Massa, afiliada ao SBT, ambos no Paraná. Na Associação Internacional de Radiodifusão (AIR), entidade que representa 17 mil emissoras de rádio e televisão nas Américas, Ásia e Europa, já ocupou a vice-presidência para a América do Sul e, atualmente, é conselheiro titular da entidade $^{10}$. E a jornalista Claúdia Slavieiro, casada com Daniel César Maranhão Khury, neto do deputado estadual biônico Aníbal Khury e do Desembargador Guilherme de Albuquerque

10 http://www.abert.org.br/web/index.php/notmenu/item/23211-daniel-pimentel-slaviero-e-reeleitopresidente-da-abert 
Maranhão, de tradicional família de juristas e desembargadores no Paraná. Daniel Maranhão Khury é cavaleiro, representante da Federação Paranaense de Hipismo. Num blog sobre o casamento do casal diz assim: "Cláudia e Daniel têm uma linda história de amizade e cumplicidade: os dois se conhecem desde criança e suas famílias sempre foram muito amigas. "Ele era amigo de colégio do meu irmão mais velho e sempre ia lá em casa. Além disso, meu avô e o avô dele foram grandes companheiros, ou seja, as famílias estavam mega felizes com o nosso casamento!"(Agosto de 2012) ${ }^{11}$.

Vale notar que inclusive que, uma das primas de Eduardo Pimentel, Paula Mussi Pimentel, filha do empresário do ramo de comunicação Luís Mussi (concessionário de canal de TV, Presidente do Jockey Club do Paraná, Ex-Secretário da Indústria e Comércio, assessor especial do Governador Requião) é casada com o irmão de Daniel Khury, o deputado estadual Alexandre Khury.

\section{Requião Filho (PMDB)}

Vice: Jorge Bernardi (Rede)

Coligação: PMDB e Rede Sustentabilidade

Maurício Thadeu de Mello e Silva, mais conhecido como Requião Filho, nasceu em Curitiba, 24 de outubro de 1979. A carreira do pai no Senado o levou para Brasília, onde acabou se formando em Direito e conhecendo a mulher da sua vida, no segundo ano da Faculdade. Em recente entrevista, Requião Filho disse que a política nunca o distanciou do pai, pelo contrário. "Se vocês olharem as fotos, vão ver que acompanhei as campanhas do meu pai desde que era criança de colo", diz. "Na Prefeitura, tem fotos da minha irmã engatinhando no gabinete. 0 meu pai sempre fez a opção de manter a família por perto"12. Trabalhou nos gabinetes do primo deputado João Arruda e do pai Roberto Requião. Foi eleito deputado estadual em 2014 com 50.167 votos.

Requião filho é um dos herdeiros políticos da família Requião Mello e Silva.

\footnotetext{
11 Disponível em http://www.constancezahn.com/claudia-slaviero-daniel-khury/. Acesso em 24 de Agosto de 2016.

12 Disponível em http://www.alep.pr.gov.br/sala de imprensa/noticias/requiao-filho-se-emociona-aoparticipar-do-programa-politica-e-viola-na-tv-assembleia. Acesso em 3 de setembro de 2016.
} 
Originária da Bahia, a família Requião destacou-se, no Paraná, no ramo comercial; Euclides Requião foi o primeiro desse nome na região. Já os Mello e Silva, também de origem nordestina, tiveram pequena notoriedade no campo da política local, tendo um maior destaque no campo intelectual. A começar por Justiniano de Mello e Silva, doutor em Ciências Sociais pela Universidade de Córdoba, primeiro da família no Paraná.

Justiniano, trisavô de Requião Filho, foi bacharel em Direito, chegou ao Paraná em 1876, dentro da itinerância do Império, com o cargo de secretário da presidência de Lamenha Lins. Exercia as profissões de jornalista, polemista e também professor do Instituto Paranaense. Fundou o Colégio Paranaense ou Liceu Curitibano, atualmente o Colégio Estadual do Paraná e mantinha uma atividade intelectual muito considerável no Estado. Foi inspiração para vários poetas simbolistas paranaenses. Na esfera política, iniciou sua carreira como deputado estadual no período provincial 1854-1889, e em 1878-1879 foi substituto de Lourenço T. Ribas de Andrade no vigente governo de Jesuíno Marcondes. Três anos mais tarde, também exerceu a legislatura como deputado na esfera paranaense, no então governo de Carlos Augusto de Carvalho. Em 1890, Justiniano participa da fundação do primeiro Partido dos Operários do Paraná, escrevendo o Manifesto de Legitimação do partido.

Seu filho, o Coronel Wallace de Mello e Silva, foi camarista em Curitiba e também desempenhou a função de deputado estadual de 1914-1915, na vigência da Primeira República, durante o governo de Carlos Cavalcante de Albuquerque. No ano de 1930, o chamado Período Revolucionário, o Coronel Wallace, como era conhecido, voltou a ocupar o posto de deputado estadual no governo de Mário Alves Monteiro Tourinho.

Por sua vez, seu neto Wallace Thadeu de Mello e Silva, que exercia a profissão de médico psiquiatra, foi indicado pelo governador Bento Munhoz da Rocha Neto para a prefeitura municipal de Curitiba em 17 de julho de 1951, e foi exonerado no dia 1o de Outubro de 1951. Posteriormente disputou a eleição para a prefeitura de Curitiba, perdendo para Ney Braga.

Como assinala Daiane Resende, a disputa de Wallace Thadeu, para a prefeitura da capital, mexeu muito com o menino Roberto Requião, que a partir desse episódio revelou precocemente uma inclinação para a política, proferindo um discurso a carro aberto em favor da candidatura do pai. Roberto Requião foi acumulando capitais na esfera política, cultural e 
econômica, através de seu bisavô, avô e, principalmente, de seu pai, seu grande inspirador. Roberto Requião de Mello e Silva entrou efetivamente para a política paranaense com 41 anos como deputado estadual, no conturbado período de redemocratização, e se manteve numa seqüência ininterrupta de êxitos eleitorais ${ }^{13}$.

Roberto Requião de Mello Silva iniciou sua vida estudantil no Colégio Belmiro César, onde foi alfabetizado pela professora Maria Augusta Juve. Prosseguiu seus estudos no Instituto de Educação do Paraná, Grupo Escolar '19 de Dezembro' e no Internato Paranaense, sendo estas escolas públicas e tradicionais de Curitiba. Seus estudos superiores foram realizados na Universidade Federal do Paraná, na qual obteve o título de bacharel em Direito, no ano de 1966, e na Pontifícia Universidade Católica do Paraná, onde concluiu o curso de Jornalismo no ano de 1964.

No período da graduação, Roberto Requião participou da militância estudantil como membro de centros acadêmicos, diretórios estudantis e no teatro universitário. Em sua juventude trabalhou na Fundação de Assistência ao Trabalhador Rural no Projeto Ponto Quatro e liderou o movimento estudantil com ideais de esquerda. Casou-se com Maristela Quarenghi de Mello e Silva, com quem tem dois três filhos: Maurício, Roberta e Ricardo.

Roberto Requião entrou na política em 1982, quando eleito deputado estadual. Depois foi prefeito de Curitiba (1986-1988), ocupou a Secretaria de Desenvolvimento Urbano no governo Álvaro Dias governador do Paraná por três mandatos (1991-1994, 2003-2007, 2007 2011) e senador pelo mesmo estado (1995-2003, 2010-2018).

Maurício Requião de Melo e Silva nasceu em Curitiba no dia 19 de setembro de 1954, filho de Wallace Tadeu de Melo e Silva e Luci Requião de Melo e Silva. Em sua cidade natal, diplomou-se em psicologia na Universidade Federal do Paraná (Ufpr) em 1979. Estudou também psicologia social na Pontifícia Universidade Católica (PUC) de São Paulo, de 1982 a 1983. Na prefeitura de Curitiba, foi secretário especial da Coordenação de Programas, de 1986 a 1987, e, entre 1987 e 1989, secretário das Administrações Regionais. Entre 1991 e 1994, presidiu a Fundação Educacional do Estado do Paraná (Fundepar). Filiado ao Partido do Movimento Democrático Brasileiro (PMDB) desde 1980, foi integrante do diretório regional de seu estado, candidatando-se a deputado federal no pleito de outubro de 1994. Eleito, foi

13 RESENDE, Daiane. . "REQUIÃO TEM RAZÃO”? HOMEM POLÍTICO E DISCURSOS: UM ESTUDO SOBRE A TRAJETÓRIA POLÍTICA DE ROBERTO REQUIÃO DE MELLO E SILVA. Curitiba, UFPR, 2015. 
empossado em fevereiro do ano seguinte, tendo participado dos trabalhos legislativos como titular da Comissão de Educação, Cultura e Desporto. Em junho de 2000 Maurício licenciou-se do cargo de assessor de gabinete de seu irmão para disputar a convenção do PMDB de Curitiba que escolheria o candidato para disputar as eleições à prefeitura da cidade no pleito de outubro do mesmo ano. Na ocasião, sua candidatura foi fortemente apoiada por Roberto Requião, descontentando lideranças na cidade e as bases do partido, que preferiam o deputado federal Gustavo Fruet como concorrente ao cargo de prefeito. 0 fraco desempenho de Maurício Requião no pleito eleitoral, obtendo apenas 10,0\% dos votos válidos, descontentou setores ligados a Fruet que começaram a afastar-se de Requião e de seu grupo político. Neste pleito elegeu-se prefeito de Curitiba o candidato do Partido da Frente Liberal (PFL), Cássio Taniguchi, apoiado pelo governador Jaime Lerner, que derrotou Ângelo Vanhoni do Partido dos Trabalhadores (PT) no segundo turno das eleições, o qual contou com o apoio de Maurício Requião. Nas articulações para a prefeitura de Curitiba de outubro de 2004, Maurício Requião liderou a corrente do partido que defendia o apoio à candidatura de Ângelo Vanhoni (PT), combatendo a facção liderada por Gustavo Fruet que defendia a candidatura própria. A derrota da tese da candidatura própria na convenção partidária realizada em junho de 2004 determinou o progressivo afastamento de Fruet em relação a Requião e seu grupo político, culminando com seu pedido de desfiliação do PMDB em setembro do mesmo ano. No pleito de outubro, Fruet declarou seu apoio ao candidato eleito no segundo turno das eleições, o ex-deputado estadual Beto Richa (PSDB), que venceu o candidato Ângelo Vanhoni (PT), apoiado pelo PMDB, com 54,5\% dos votos válidos.

Outros familiares fizeram parte dos governos de Roberto Requião entre 2003 e 2010. Heitor de Mello e Silva (primo) foi diretor de investimentos da Sanepar, Daniele de Mello e Silva (sobrinha) foi diretora de secretaria de Saúde, João Arruda (sobrinho) foi diretor da Companhia de Habitação do Paraná, Maristela Requião (esposa) foi diretora do Museu Oscar Niemayer, Paikan de Mello e Silva (sobrinho) da Paraná Educativa e Wallace de Mello e Silva, também com cargo no governo.

Requião Filho aparece com o terceiro maior patrimônio entre os nove candidatos a prefeito, com R\$1,9 milhão declarados. 0 bem de maior valor é uma unidade em um condomínio (R\$1,4 milhão). 


\section{Ney Leprevost (PSD)}

Vice: João Guilherme Moraes (PSC)

Coligação: PSD, PSC, PEN, PPL, PTC, PSL e PCdoB.

Ney Leprevost nasceu em Curitiba no dia 26 de outubro de 1973. Iniciou sua carreira aos 13 anos de idade como comentarista esportivo. Dois anos mais tarde já tinha seu próprio programa na Rádio Difusora 590. Aos 22 anos foi eleito para o seu 1ํ mandato na Câmara Municipal de Curitiba, sendo nesta época o vereador mais jovem da cidade. Três anos mais tarde, em 1999, foi convidado para assumir a Secretaria de Estado do Esporte e Turismo do governo Lerner, tornando-se o secretário mais jovem do Brasil.

Em 2000 e 2004 reelegeu-se como vereador na Câmara Municipal de Curitiba e no ano de 2006 se candidatou a deputado estadual do Paraná e elegeu-se 53.471 votos, sendo o deputado estadual mais votado entre os que tentaram pela primeira vez o cargo. Em 2010 foi reeleito deputado estadual sendo o mais votado de Curitiba, com cerca de 80 mil votos.

Para a campanha para Prefeito, dono de uma das maiores coligações, com sete siglas, Leprevost decidiu por um vice "não político", o médico João Guilherme Moraes (PSC), ligado a Ratinho Jr. (PSD), que sonha suceder Richa no governo do Estado em 2018. Ney Leprevost (PSD), o último a solicitar o registro de candidatura, disse possuir um patrimônio no valor de $\mathrm{R} \$ 860,4$ mil.

0 avô de Ney, que tinha o mesmo nome, nasceu em Curitiba no dia 23 de outubro de 1911. Filho de José Leprevost e de Angelina Curial. Estudou no antigo Ginásio Paranaense, da rua Ébano Pereira. Formou-se em Direito pela Faculdade de Direito da Universidade do Paraná em 1936. Começou sua carreira como fiscal do Instituto de Aposentadoria e Pensões dos Comerciários (1935-1936). Serviu como primeiro Presidente da Junta de Conciliação e Julgamento do Paraná, origem do Tribunal do Trabalho. Integrou o conselho da Ordem dos Advogados de 1937 a 1947.

Atuante no Partido Social Democrático (PSD), foi candidato a Deputado por duas vezes, sendo eleito como suplente. Exerceu entre 1947 e 1948 o cargo de Procurador-Geral do Estado. Prefeito de Curitiba de 1948 a 1949. Foi Procurador Fiscal até 1954, cargo no qual se 
aposentou. Foi Procurador no Tribunal de Contas de 1947 a 1957. Empresário, edificou o prédio da Galeria Tijucas, marco da cidade nas décadas de 1950 e 1960. Morreu em 6 de setembro de 1979.

O pai, Luiz Antonio Leprevost, nasceu em 30 de setembro de 1953. Formou em Direito na Faculdade de Direito de Curitiba em 1976.

Durante da faculdade foi Operador de Créditos e financiamentos do Grupo Financeiro Ipiranga de 1971 a 1974. Depois foi Auxiliar de Gerencia no Banco Bamerindus do Brasil S/A de 1975 a 1978. Ocupou diversos cargos no Banco Real de São Paulo entre 1978 e 1983. Foi Diretor Administrativo Financeiro do Banestado S/A de 1984 a 1987. Foi Diretor Estatutário da Hermes Macedo Financiadora S/A de 1990 a 1992. Diretor de Recursos Humanos e Diretor de Serviços - Telecomunicações do Paraná S/A. - Telepar de 1992 a 1993. Diretor Técnico e de Operações - CIC - Companhia de Desenvolvimento de Curitiba em 1995. Diretor de Finanças e Patrimônio da Paranáprevidência, Vice-Presidente e 1ํㅜ Tesoureiro da Associação Comercial do Paraná de 1991 a 1993. Conselheiro dp Clube Curitibano de 1997 a 2010; Conselheiro - Associação Comercial do Paraná em 2002. Conselheiro da Federação das Indústrias do Estado do Paraná em 2002. Conselheiro do Graciosa Country Clube em 2011. Foi membro do conselho de administração da SANEPAR de 2011 a 2015, depois diretor da subsidiária Copel Renováveis,

0 tio de Ney, José Carlos Leprevost, nasceu em Curitiba no dia 19 de novembro de 1940, filho de Nei Leprevost e de Estela Surugi Leprevost. Bacharelou-se em ciências jurídicas e sociais na Faculdade de Direito da Universidade do Paraná em 1962. Ainda no Paraná, exerceu os cargos de assistente técnico da presidência do Tribunal de Contas do Estado (TCE), chefe de gabinete da Secretaria de Agricultura e oficial-de-gabinete da Secretaria do Interior e Justiça.

No pleito de novembro de 1966, elegeu-se deputado federal por seu estado na legenda da Aliança Renovadora Nacional (Arena), partido de sustentação política ao regime militar instaurado no país em abril de 1964. Em novembro de 1970, foi reeleito na mesma legenda. Em janeiro de 1975 deixou definitivamente a Câmara dos Deputados. Afastado da política, passou a dedicar-se às atividades na área da mineração e constituiu as empresas Leprevost e Cia. Ltda., Mineração Morretes Ltda. e Mineração São Brás S.A., em associação ao grupo de 
assistência médica paulista Samcil. Paralelamente às atividades nesse ramo, continuou no TCE-PR. Em 1989, foi convidado pelo governador de Rondônia Jerônimo Santana (1987-1991) a assumir a Secretaria de Estado. Neste período ocupou o cargo de presidente da Companhia de Mineração de Rondônia (CMR). De volta ao Paraná, retomou suas atividades no TCE, aposentando-se em 1993. A partir de então, passou a centralizar seus esforços para reativar a Metalurgia de Chumbo da Plumbum, implantada no vale da Ribeira. Entretanto, não foi bemsucedido em seu empreendimento, pois a empresa fechou as postas em 1995 em meio a acusações de danos ao meio-ambiente e à saúde dos habitantes do município de Adrianópolis, localizado na região.

O irmão de Ney é João Guilherme Leprevost, dono do Bar da Brama e da CWB Brasil, empresa de entretenimento e organizadora de eventos musicais e culturais, alguns financiados pela Prefeitura Municipal de Curitiba. As conexões entre os poderosos são curiosas, atravessam conjunturas e o jogo situação-oposição. 0 deputado Ney Leprevost declarou seu orgulho pelo fato do seu grande amigo Alexandre Khury ter sido eleito $1^{\mathrm{o}}$ Secretário da Assembléia Legislativa. Khury começou sua vida pública como estagiário da Secretaria Estadual de Esporte e Turismo quando Leprevost, fiel aliado político de seu avô, era o responsável pela pasta ${ }^{14}$.

\section{Maria Victoria (PP)}

Vice: Luciano Pizzatto (PRTB)

Coligação: PP, PMB, PR, PRTB, PHS e SD.

Maria Victória Borguetti Barros é filha do casal Cida Borguetti e Ricardo Barros. Nasceu em 1 de fevereiro de 1992 em Maringá. Em 1995 muda-se para Curitiba onde cursou o ensino fundamental. Em 2007 cursa o primeiro ano do ensino médio em Lugano, na Suíca. Em 2008 retorna para Curitiba para estudar na International School of Curitiba. Estudou Turismo na Suíça. Em 2010 estagiou por 5 meses no hotel Sofitel em Suzhou na China. Atualmente cuida dos negócios da família: a St. James International School, a Borghetti Barros Imóveis e a

14 RICARDO DE OLIVEIRA, Famílias, poder e riqueza: redes políticas no Paraná em 2007. Disponível em http://www.scielo.br/scielo.php?script=sci_arttext\&pid=S1517-45222007000200008 
Construtora Magalhães Barros' ${ }^{15}$. Foi eleita deputada em 2014 com 45.870 votos. Perguntada sobre seu "sangue político", ela respondeu "Eu faço isso desde a minha primeira infância, desde os dois anos. Eu com quatro anos, em 94 também pedindo votos pro Jaime Lerner, Carvalhinho, FHC era candidato à Presidência da República, meu pai era candidato a deputado federal"16.

A deputada Maria Victória tem 24 anos e é, de longe, a mais jovem dos candidatos à prefeitura de Curitiba nas eleições deste ano. Maria Victoria declarou bens no valor de R\$ 897.880,05 mil nas eleições de 2016. A maior parte ( $\mathrm{R} \$ 700$ mil) diz respeito a um empréstimo bancário. Sua evolução patrimonial foi maior que 5.000\% em apenas dois anos, de acordo com a declaração feita à Justiça Eleitoral. Em 2014 ela declarou possuir um patrimônio de $\mathrm{R} \$ 17.100,00$.

Por um lado, Maria Victoria é a mais nova herdeira dos Barros, família presente na política maringaense desde o início da história do Município. Seu avô, Silvio Magalhães Barros, chegou em Maringá no início da década de 1940.

Silvio Magalhães Barros nasceu em 03 de setembro de 1927 em Auruoca-MG, filho de José Magalhães Barros e Olga Quiarelli. Com a família residindo em São Paulo-SP, Silvio se muda para Mandaguari após o falecimento da mãe para atuar como agrimensor. Como havia a necessidade de demarcação das terras de Maringá, Silvio decide mudar-se para o então distrito de Mandaguari, atuando nesta profissão. 0 primeiro cargo público ocupado por Silvio Magalhães Barros5 foi a vereança. Suplente durante a 3로 Legislatura (1960-1964), com 237 votos, Silvio assumiu ao longo do mandato, representando a UDN (União Democrática Nacional). Novamente candidato, foi eleito para 4⿳⺈ L Legislatura (1964-1969), com 260 votos. Neste ínterim, em 1966 foi eleito Deputado Estadual, ocupando a cadeira de 1967 até 1970, quando foi eleito Deputado Federal pelo MDB (Movimento Democrático Brasileiro), com 29.618 votos.

Porém, a maior marca de Silvio Magalhães Barros na política foi a conquista da Prefeitura Municipal de Maringá em 1972. Dois anos após o término do mandato como prefeito, Silvio faleceu - em 1979.

\footnotetext{
${ }^{15}$ A família Barros na política paranaense. Tiago Valenciano. Anais do XI Seminário de Ciências Sociais - 21 a 25 de Outubro de 2013. Disponível em http://www.dcs.uem.br/xiseminario/gtvi/a7.pdf

16 Disponível em http://paranaportal.uol.com.br/politica/herdeira-da-familia-barros-vai-em-busca-da-herancalernista/. Acesso em 13 de setembro de 2016.
} 
Foi da união entre Silvio Magalhães Barros e Bárbara Cecily Netto Barros em dezembro de 1954 que se iniciou a carreira política da família Barros. Da união vieram os filhos: Christina Helena Barros (já falecida), Beatriz Barros, Bárbara Magalhães e os dois que enveredaram na vida pública - Ricardo José Magalhães Barros e Silvio Magalhães Barros II.

Ricardo José Magalhães Barros nasceu em 15 de Novembro de 1959. Formado em Engenharia Civil pela Universidade Estadual de Maringá. Casou-se com Débora Kasprovicz e, da união, nasceram as filhas Raffaele e Andressa. Divorciou-se de Débora e contraiu núpcias com Maria Aparecida Borghetti, tendo a filha caçula Maria Victória Borghetti Barros. A carreira política de Ricardo iniciou-se em 1988. Foi candidato a Prefeito de Maringá e foi eleito com 38.902 votos. O partido o qual representava era o PFL (Partido da Frente Liberal), recém-criado na ocasião e que elegeu dois parlamentares para a Câmara Municipal.

Após o término do mandato frente ao Município, foi candidato a Deputado Federal em 1994 ainda pelo PFL, obtendo 54.049 votos - o oitavo mais votado do Paraná. Já em 1998, foi reeleito Deputado Federal pelo PPB (Partido Progressista Brasileiro), atual Partido Progressista, o qual se mantém fi liado até hoje. Com 68.919 votos, ampliou o eleitorado e foi consolidando o posto de Deputado Federal que representa Maringá e região. Mantendo a tendência de ampliar a votação, Ricardo reelegeu-se para o terceiro mandato em 2002, com 118.036 votos. Com 130.085 votos, foi eleito para o quarto mandato consecutivo em 2006, obtendo seu maior êxito nas urnas até então. Em 2010 veio e a primeira derrota de Ricardo. Foi candidato a Senador pelo PP, na chapa encabeçada para o Governo do Estado por Beto Richa (PSDB). Apesar da expressiva votação (2.190.539 votos) Ricardo não foi eleito. Após a derrota para o Senado, Ricardo Barros foi indicado para assumir a Secretaria Estadual da Indústria, do Comércio e de Assuntos do Mercosul no governo Richa. Com o processo de impeachment de Dilma, Michel Temer indicou Ricardo como Ministro da Saúde. É proprietário de uma escola, de uma imobiliária e de uma construtora.

0 irmão de Ricardo é Silvio Magalhães Barros. Irmão de Ricardo, nasceu em 11 de dezembro de 1956. Também é formado em Engenharia Civil, sendo especialista em Engenharia Sanitária e Ambiental. Atuou na área turística em Manaus, sendo Secretário Estadual no Amazonas. Disputou a Prefeitura de Maringá pela primeira vez em 1996, obtendo 31.081 votos pelo PFL. Não disputou nenhum cargo para o Poder Legislativo em sua carreira política. Foi eleito pela primeira vez em 2004 pelo PP, obtendo 43.333 votos no primeiro 
turno e 92.052 no segundo turno para a Prefeitura de Maringá. Reeleito em 2008 (o primeiro da história), obteve 104.820 votos, representando 57\% do eleitorado. Ingressou no PHS e é favorito para prefeitura de Maringá em 2016.

A mãe de Maria Victória é Maria Aparecida Borghhetti Barros, natural de Caçador, Santa Catarina. Nasceu em 18 de fevereiro de 1965. Formada em Administração Pública pela Unisul e Especialista em Políticas Públicas pela UFRJ, é proprietária de uma agência de comunicação e marketing e já apresentou programa de TV veiculado em Curitiba. Iniciou sua militância na juventude do PDS, filiando-se ao PFL (que o marido também integrava), depois passou pelo PP até assumir a Presidência Estadual do Partido Republicano da Ordem Social PROS. A primeira candidatura de Cida Borghetti (seu usual nome político) foi em 2000, quando disputou a Prefeitura Municipal de Maringá pelo PP. Obtendo 22.931 votos, terminou a disputa em quarto lugar. Dois anos após, em 2002, foi candidata a Deputada Estadual, dobrando com o marido então candidato a Deputado Federal. Obteve 53.225 votos, elegendose. Em 2006 foi novamente candidata, sendo eleita com 66.492 votos. A última candidatura ocorreu em 2010, quando disputou uma vaga para a Câmara dos Deputados e elegeu-se com 147.910 votos, a maior votação do casal em um pleito para o legislativo federal. Em 2014 foi eleita vice-governadora na chapa com Beto Richa e já é pré-candidata para o governo do Paraná em 2018.

A família Borguetti está presente em outros espaços políticos. 0 irmão de Cida, Juliano Borghetti, foi Secretário de Esportes (2001-2004) de Curitiba e Vereador na mesma cidade, de 2008 a 2012, pelo PP. É casado com Renata Bueno, que foi Vereadora no mesmo período em Curitiba e atualmente é Deputada do Parlamento Italiano. Filha do ex-Prefeito de Campo Mourão e Deputado Federal, Rubens Bueno. Sua irmã está lotada no gabinete de Fábio Camargo no Tribunal de Contas. Sua sobrinha Alana Borghetti Violanni atuava como assessora, lotada na Secretaria Geral da Presidência, ganhando um salário de $\mathrm{R} \$ 10.352,52$ e atuava na área de cerimonial do Tribunal Regional do Trabalho da 9a Região (TRT9). No gabinete de Cida, trabalha Sionara Maria Diedrichs Nascimento, irmã da desembargadora Rosemarie Diedrichs Pimpão, que foi presidente do TRT-9 de 2011 a $2013^{17}$.

17 Disponível em http://www.gazetadopovo.com.br/vida-publica/justica-e-direito/apos-criticas-sobrinha-dericardo-barros-pede-exoneracao-do-trt-9-bas9qeksoj21uusiwi977o4y1. Acesso em 13 de setembro de 2016. 
O candidato a vice na chapa de Maria Victória é Luciano Pizzatto (PRTB). Empresário madereiro, foi deputado federal. Declarou para Justiça Eleitoral em 2016 R 7,2 milhões em bens.

\section{Tadeu Veneri}

Vice: Nasser Ahmad Allan (PT)

Chapa pura

Tadeu Veneri é filho e neto de ferroviários, nasceu em União da Vitória e mudou-se em 1972, para trabalhar em Curitiba. Em 1974, começou a estudar Psicologia, na Universidade Católica do Paraná e Universidade Federal do Paraná. Ex-funcionário do Banco do Brasil, Veneri começou sua militância política no movimento sindical. Seus mandatos parlamentares foram construídos nas lutas sindicais. Ele atuou em todo o estado, na década de 70, ajudando na organização dos trabalhadores e na construção da oposição sindical dos bancários em vários municípios do interior.

Veneri é filiado ao PT desde 1988. 0 primeiro mandato de Veneri na Assembleia Legislativa foi em 2003, tendo sido reeleito em 2006, 2010 e 2014. Antes, Veneri foi vereador em Curitiba, entre 1995 e 2002. Tadeu Veneri (PT) é o segundo mais "pobre" entre os candidatos a prefeito de Curitiba neste ano, com um patrimônio de R \$ 342,2 mil.

\section{Xênia Melo (PSOL)}

Vice: Rodolfo Jaruga (PSOL)

Coligação: Psol e PCB

Xênia Mello é filha de Pedro Aparecida Mello e Roseli dos Santos. Nasceu no Itatiaia, bairro da periferia de Curitiba. Graduou-se em Direito e é Mestranda em Sociologia pela Universidade Federal do Paraná (UFPR). Especialista em Literatura Brasileira e História Nacional 
pela Universidade Tecnológica Federal do Paraná (UTFPR). Atualmente é membro do Conselho Municipal dos Direitos da Mulher em Curitiba. Em 2012, foi candidata a vereadora e fez 1.037 votos. Xênia declarou não possuir nada em seu nome.

\section{Ademar Pereira (Pros)}

Vice: Porfírio Vengue (Pros)

Chapa pura

Ademar Pereira é filho de agricultores, começou a trabalhar aos 14 anos, como auxiliar de escritório na área de informática. Foi corretor de imóveis e proprietário de agência de publicidade antes de entrar no setor educacional, proprietário de uma rede de colégio. Diretor da escola Atuação e dono do Espaço Torres. Atualmente é vice-presidente da Federação Nacional das Escolas Particulares (Fenep). Entre 2009 e 2012, foi presidente do Sindicato dos Estabelecimentos Particulares de Ensino do Estado do Paraná (Sinepe). 0 empresário Ademar Pereira é o candidato que declarou o maior patrimônio à Justiça Eleitoral: R\$ 4,1 milhões.

\section{Afonso Rangel (PRP)}

Vice: Rick Villar (PRP)

Chapa pura

Afonso Rangel é formado em Ciências Aeronáuticas e construiu a vida como empresário da área de educação superior e foi piloto de Stockcar Atualmente, Rangel é Pró-Reitor de Planejamento e Avaliação da Universidade Tuiuti do Paraná. Em 2012 disputou a vereança pelo PTB e obteve 937 votos. Apresentou um patrimônio declarado de R\$1,2 milhão. Ele disse possuir R\$ 426 mil como sócio da Sociedade Educacional Tuiuti. 


\section{Conclusão}

Uma análise geral dos candidatos a Prefeitura de Curitiba em 2016 nos leva a uma constatação: dos nove candidatos, cinco vem de famílias tradicionais da política. E é exatamente estes cinco candidatos que tem as maiores coligações na disputa. Tanto o atual prefeito, Gustavo Fruet, como seus principais adversários, Requião Filho, Rafael Greca, Ney Leprevost e Maria Victoria Barros, pertencem a famílias tradicionais da política. Todos são herdeiros diretos e indiretos das velhas oligarquias que dominam o Paraná para tentar gerir o Estado com suas novas gerações. Os partidos não são mais do que braços dessas famílias.

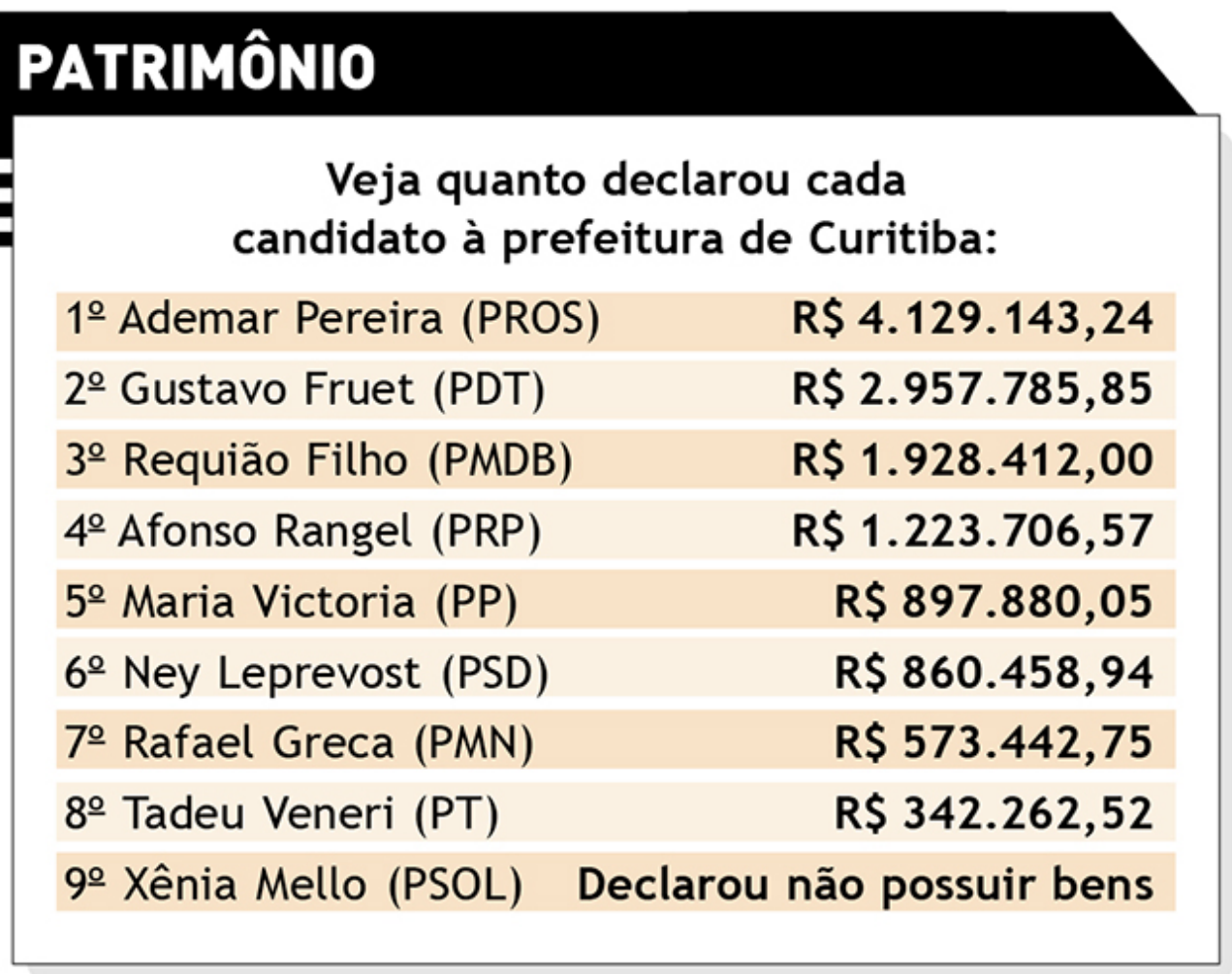

Fonte: http://www.bemparana.com.br/noticia/459544/novato-e-omais-rico-dos-candidatos-a-prefeito--veja-o-patrimonio 